Methods: Prospective, observational, cross-sectional study. Carotid Doppler was performed on patients in the outpatient clinic with a diagnosis of gout from November 2019 to 2020 of the rheumatology service of the Hospital Docente Padre Billini and healthy controls. Inclusion criteria, patients> 18 years, diagnosis of monosodium urate deposits arthritis according to the ACR / EULAR 2015 classification criteria, carotid Doppler, measurement of the cIMT. Controls without disease, matched by sex and age. The data was analyzed with SPSS V23 for Windows 10. Results: Of 37 patients with a diagnosis of arthritis due to deposition of monosodium urate crystals, (34) met inclusion criteria, 100\% male, 34 healthy controls. Average of 61.5 years. Average of the disease 8.2 years. Distribution $61 \%$ (21) intercritical gout, 32\% (11) chronic tophaceous gout, $0.5 \%(2)$ acute gouty arthritis. Comorbidities 67\% (23) dyslipidemia, 35\% (12) hyperglycemia. 26\% (9) presented arterial hypertension. 20\% (7) have diabetes mellitus. 58\% (20) are alcohol drinkers, $11 \%$ (4) smokers. Mean uric acid $8.6 \mathrm{mg} / \mathrm{dl}$ at Doppler, $52 \%$ (18) elevated serum creatinine. Carotid Doppler in patients with gout showed a $55 \%$ (19) increase in the cIMT > $0.9 \mathrm{~mm}$, with a mean of $2.03 \mathrm{~mm}$ (1.95 SD). Carotid Doppler in healthy controls $17 \%$ (6) increased cIMT, mean of $1.8 \mathrm{~mm}(2.2$ SD) $(P=0.040)$. Patients with gout had $29 \%(10)$ atheromatous plaques, $17 \%$ (6) calcified plaques versus $14 \%$ (5) atheromatous plaques, $8 \%(3)$ calcified in healthy controls.

Conclusion: Our study showed that half of the patients with gout had increased cIMT compared to a third of the healthy controls. The presence of atheromatous and calcified plaques was mainly associated with dyslipidemia, so we can conclude that the evaluation of the intima-media thickness by carotid Doppler allows it to be a predictor of cardiovascular disease in patients with gout.

REFERENCES:

[1] Choi HK, Curhan G (2007) Independent impact of gout on mortality and risk for coronary heart disease. Circulation 116:894-900

[2] Feig DI, Kang DH, Johnson RJ (2008) Uric acid and cardiovascular risk. N Engl J Med 359:1811-1821

[3] Choi, HK. Rho, Y-H., Zhu, Y., Cea-Soriano, L., Aviña-Zubieta, JA. Zhang, Y. The risk of pulmonary embolism and deep vein thrombosis in rheumatoid arthritis: A UK population-based outpatient cohort study. Ann Rheum Dis. 2013; 72 (7): 1182-7

[4] Gkaliagkousi, E., Gavriilaki, E., Doumas, M., Petidis, K., Aslanidis, S., Stella, D. Cardiovascular risk in rheumatoid arthritis: Pathogenesis, diagnosis, and management. J ClinRheumatolPract Rep Rheum Musculoskelet Dis. 2012; 18 (8): $422-30$

[5] Cukurova S, Pamuk ÖN, Ünlü E, Pamuk GE, C, akir N. Subclinical atherosclerosis in gouty arthritis patients: a comparative study. Rheumatol Int. 2012; 32(6):1769-73.

Disclosure of Interests: None declared.

DOI: 10.1136/annrheumdis-2021-eular.2747

\section{AB0636 ASYMPTOMATIC HYPERURICEMIA IN INFLAMMATORY RHEUMATIC DISEASES}

A. Fonturenko ${ }^{1}$, R. Bashkinov ${ }^{1,2}$, V. Mazurov ${ }^{1,2}$, M. Petrova ${ }^{2,3}$, O. Inamova ${ }^{2,3}$, I. Gaydukova ${ }^{1,2}$. 'Clinical Rheumatological Hospital No25, Center for diagnosis and treatment of autoimmune diseases, Saint-Petersburg, Russian Federation; ${ }^{2}$ North-Western State Medical University named after II Mechnikov, Department of Therapy, Rheumatology, Examination of Temporary Disability and Quality of Medical Care named after E. E. Eichwald, Saint-Petersburg, Russian Federation; ${ }^{3}$ Clinical Rheumatological Hospital No25, City Clinical Center of Gout, Saint-Petersburg, Russian Federation

Background: Uric acid (UA) is well-known biomarker of cardiovascular risk and inflammation. However, the data about interrelations between asymptomatic hyperuricemia $(\mathrm{AHU})$ and rheumatic diseases $(\mathrm{RD})$ are limited and contradictory [1]. Objectives: to identify the occurrence of $\mathrm{AHU}$ in pts with different RD and to evaluate the interrelations between the AHU and clinical features of the RD. Methods: The study included data from 822 pts with AHU and RD involved in the Saint-Petersburg Register of Pts with AHU in period from the 01jan2000 to the 01apr2020. The AHU was defined as the serum level of uric acid (UA) that exceeded $360 \mu \mathrm{mol} / \mathrm{l}$ without signs of gouty arthritis. Pts with the secondary reasons of $\mathrm{AHU}$ (an oncologic diseases, late stages of chronic kidney disease, ets), and inflammatory diseases another than RD were excluded from the study.

Patient's demographical characteristics, duration of AHU, level of UA, activity of RD, ESR, CRP, urate-lowering therapy (ULT) were analyzed. The study was approved by local ethic committee. Statistics was performed with SPSS17.

Results: Characteristics of the Patients with the RD and $\mathrm{AHU}$ are present in Table 1. The duration of $A H U$ in pts with the RD was $3.4 \pm 3.4$ [0.08-18] years, mean duration of follow-up $2.7 \pm 4.0$ years, mean number of visits during the period of follow-up was $3,2[\min 1$; $\max 7]$, ESR $26.0 \pm 14.1 \mathrm{~mm} / \mathrm{h}$, CRP $19.6 \pm 21.0 \mathrm{mg} / \mathrm{l}$
Table 1. Characteristics of the Patients with the Rheumatic diseases and asymptomatic hyperuricemia.

\begin{tabular}{lllll}
\hline & $\begin{array}{l}\text { Age, years } \\
\text { (Mean } \pm \text { SD) }\end{array}$ & Male, \%** & $\begin{array}{l}\text { Serum UA, } \mu \text { mol/l l } \\
(\text { Mean } \pm \text { SD) }\end{array}$ & $\begin{array}{l}\text { Normalization of UA during } \\
\text { the follow-up, } n(\%)\end{array}$ \\
\hline $\mathrm{RD}, \mathrm{n}=822$ & $56.7 \pm 14.5$ & 40.27 & $493.3 \pm 98.5$ & $242(29.44)^{\# \#}$ \\
$\mathrm{RA}, \mathrm{n}=329$ & $64.2 \pm 12.1$ & 3.74 & $504.8 \pm 107.5^{\#}$ & $99(30.09)^{\# \#}$ \\
$\mathrm{PsA}, \mathrm{n}=149$ & $56.6 \pm 12.9$ & 53.69 & $531.5 \pm 94.9^{\#}$ & $32(21.48)^{\# \#}$ \\
$\mathrm{SpA}, \mathrm{n}=107$ & $45.6 \pm 15.1^{\star}$ & 33.43 & $520.8 \pm 86.5^{\#}$ & $18(16.82)^{\# \#}$ \\
$\mathrm{SLE}, \mathrm{n}=137$ & $50.3 \pm 14.1^{*}$ & 20.44 & $451.6 \pm 91.4$ & $57(41.61)$ \\
$\mathrm{SSc}, \mathrm{n}=57$ & $61.0 \pm 12.4$ & 22.81 & $456.2 \pm 99.5$ & $20(35.09)$ \\
$\mathrm{SD}, \mathrm{n}=43$ & $62.0 \pm 10.7$ & 16.28 & $442.4 \pm 107.5$ & $16(37.21)$ \\
\hline
\end{tabular}

$\mathrm{RD}$ - rheumatic disease; RA — rheumatoid arthritis; PsA — psoriatic arthritis; SpA — spondy loarthritis; SLE — systemic lupus erythematosus; SSc — systemic sclerosis; SD — Sjogren's disease; * $-p<0.001$ for the differences with RD, RA, PsA, SSc, SD; ${ }^{* *}-p<0.01$ for all intergroup differences; ${ }^{\#}-p<0.01$ for the differences with RD, RA, SSc, SD; $\#-p<0.01$ for the differences with RA, SSc, SD.

Were revealed the interrelations between the level of UA and ESR (Spearmen's $\mathrm{R}=0.1, \mathrm{p}=0.01$ ), and UA and CRP (Spearmen's $\mathrm{R}=0.12, \mathrm{p}=0.001$ )

The level of UA in male pts was 507.0 [361-940], in female pts 450.0 [361-1010] $\mu \mathrm{mol} / \mathrm{A}$ ( $p<0.0001$ ), in SLE pts with elevated anti-nuclear factor (ANF) UA was 429 [361-940] and with normal 494 [361-973] $(\mathrm{p}<0.0001)$. In pts with high and low RD activity UA was 490 [361940] and 454 [363-1010]) $\mu \mathrm{mol} / \mathrm{r}$ respectively, $(p<0.0001)$. The higher UA level was found in any $\mathrm{RD}$ as compared with UA in low activity of the same $\mathrm{RD}$ ( $\mathrm{p}<0.0001$ for all the differences). Normalization of UA was found in $243(29.6 \%)$ pts, lack of normalization of UA in $434(52.8 \%)$ of cases, $n=677$, Table 1 . ULT received $219(26.6 \%)$ pts. Normalization of UA without ULT was registered in 16 (1.9\%) of the pts.

Conclusion: UA level is higher and normalize less often in patients with $\mathrm{SpA}$ and PsA as compered with RA, SLA, SSc and SD pts. In any of analyzed rheumatic diseases the level of UA is higher in male pts and in pts with high disease activity. REFERENCES:

[1] K.Bosmansky, M. Ondrasik. Ter Arkh.1987;59(4):22-5

Disclosure of Interests: None declared.

DOI: 10.1136/annrheumdis-2021-eular.2980

\section{AB0637 THE STATE OF GOUT MANAGEMENT IN WALES RHEUMATOLOGY UNITS}

\section{Saleh ${ }^{1} .{ }^{1}$ University Hospital of Wales, Rheumatology, Cardiff, United Kingdom}

Background: Gout is the most common inflammatory arthritis with both the prevalence and incidence showed significant rise in the UK in recent years ${ }^{1}$.

The most frequent reasons for referral from primary care were diagnostic uncertainty $54 \%$, failure to respond to primary care management $28 \%$, and complex comorbidity $25 \%{ }^{2}$.

From primary care perspective, increased urate level $(p=0.0001)$, young age $(p=0.009)$, fewer comorbidities $(p=0.039)$ constituted the most common risk for gout General Practice consultations and in addition to poor compliance to urate lowering treatment ULT $(p=0.004)$ and lower CVS risk scores $(p=0.038)$ these all factors comprised the independent risk factors for Gout flares ${ }^{3}$.

Objectives: To compare the management of gout in the rheumatology services in Wales against the 2017 British Society for Rheumatology (BSR) Guidelines.

Methods: •A descriptive study over an 8-week period from January to February 2019, used Simple Analysis in calculating the frequency (\%).

-Data were collected from notes of 79 patients referred to rheumatology departments across Wales using the British Society for Rheumatology (BSR) 2017 Gout Guidelines Audit Tool.

-The audit cohort comprised $62 \%$ of chronic gout patients and $38 \%$ of acute admissions

Results:

\begin{tabular}{|l|l|l|}
\hline Gout Audit & $\begin{array}{l}\text { All Wales 2019 } \\
\text { (BSR Guidelines 2017) }\end{array}$ & $\begin{array}{l}\text { UK National Audit } \\
\text { (BSR Guidelines 2007) }\end{array}$ \\
\hline Education material & $54 \%$ & No available data \\
\hline Newly start ULT & $59 \%$ & $42 \%$ \\
\hline ULT was prescribed & $87 \%$ & $33 \%$ \\
\hline ULT was continued & $78 \%$ & $76 \%$ \\
\hline Prophylaxis & $94 \%$ & $94 \%$ \\
\hline Febuxostat & $21 \%$ & $10 \%$ \\
\hline ULT main indication & $>2$ attacks (71\%) & Tophi (81\%) \\
\hline eGFR $<60$ ml/min & $40 \%$ & $30 \%$ \\
\hline Urate level checked & $83 \%$ & $72 \%$ \\
\hline Urate $<300$ umol/L & $36 \%$ & $25 \%$ \\
\hline Urate $<360$ umol/L & $58 \%$ & $45 \%$ \\
\hline
\end{tabular}


Conclusion: -Gout management by rheumatologists across Wales concords well with the recent BSR guidelines for most audit standards and showed an improvement in percentage of patients who achieved a target serum uric acid level $<300$ and $<360 \mathrm{umol} / \mathrm{L}$ according to the BSR and EULAR guidelines, respectively.

-Areas for improvement include documentation of Patient Education, improvement of audit tool (Age, Alcohol, current ULT).

- To spread the message to primary care setting, where gout is predominantly managed, to ensure that ULT is optimized to achieve target serum uric acid level to benefit patients.

REFERENCES:

[1] Kuo C, Grainge MJ, Mallen C, et al Rising burden of gout in the UK but continuing suboptimal management: a nationwide population study, Annals of the Rheumatic Diseases 2015;74:661-667.

[2] *Management of gout by UK rheumatologists: a British Society for Rheumatology national audit.Roddy E, Packham J, Obrenovic K, Rivett A, Ledingham JM.Rheumatology (Oxford). 2018 May 1; 57(5):826-830.

[3] Callear J, Blakey G, Callear A, et al Gout in primary care: Can we improve patient outcomes? BMJ Open Quality 2017;6:u210130.w4918. doi: 10.1136/ bmjquality.u210130.w4918

Acknowledgements: Dr Martin Bevan for supervising the work and Rheumatology Units across Wales for collecting data and the British Society for Rheumatology in formulating the audit tool.

Disclosure of Interests: None declared.

DOI: 10.1136/annrheumdis-2021-eular.2985

\section{\begin{tabular}{|l|l}
\hline AB0638 & CYTOKINE STATUS IN METABOLIC SYNDROME IN
\end{tabular} PATIENTS WITH GOUTY ARTHRITIS}

K. Zhigulina ${ }^{1}$, S. Spitsina ${ }^{1,2} .{ }^{1}$ Federal State Budgetary Educational Institution of Higher Education "Volgograd State Medical University" of the Ministry of Healthcare of the Russian Federation, Department of hospital therapy, Volgograd, Russian Federation; ${ }^{2}$ Federal State Budgetary Institution "Research Institute of Clinical and Experimental Rheumatology named after A.B. Zborovsky," Clinical Biochemical Laboratory, Volgograd, Russian Federation

Background: Gout is an inflammatory and metabolic disease. Hyperuricemia can contribute to inflammation, hypertension and cardiovascular disease, adipogenesis and lipogenesis, impaired insulin and glucose metabolism, and the development of liver disease. In turn, non-alcoholic fatty liver disease is the most common chronic liver disease worldwide; is closely related to obesity, type 2 diabetes mellitus, dyslipidemia and other metabolic risk factors included in metabolic syndrome (MS). Interest in the problem of MS has not faded for many years, which is associated with its extremely rapid spread in the world.

Objectives: To assess the cytokine status in patients with gouty arthritis (GA) in combination with metabolic syndrome (MS).

Methods: There were 60 patients with reliable GA under observation. Among the surveyed men and women accounted for $60 \%$ and $40 \%$, respectively, with an average age of 54 years, an average duration of the disease of 8 years. A family history of gout was present in $42 \%$ of patients. The onset of gouty arthritis was observed at $35.6 \pm 10$ years. Hypouricemic therapy was prescribed in $70 \%$ of patients. Thirty-six patients were diagnosed with the tofus form, 24 had no tofus. Patients were included in the study during arthritis remission. Blood samples were taken for general clinical and biochemical analyzes (ESR according to Westergren and uric acid levels were estimated), as well as for determination of serum concentrations of TNF-alpha and IL-6 by enzyme immunoassay.

Results: The patients were divided into two groups: group 1 - 40 people with GA without signs of MS, group 2 - 20 patients with GA and MS. Patient groups were matched by sex, age, form and severity of the disease. In the 1st group, the body mass index ranged from 28.00 to $34.25 \mathrm{~kg} / \mathrm{m} 2$, in the 2nd group - from 29.05 to $49.39 \mathrm{~kg} / \mathrm{m} 2$. In patients with isolated gout, the waist in men averaged $96 \mathrm{~cm}$, in women $-86.5 \mathrm{~cm}$; in the 2 nd group: in men $-98 \mathrm{~cm}$, in women $-88 \mathrm{~cm}$. Among the criteria for MS, in addition to abdominal obesity, in the 2nd group, arterial hypertension (in 64\%), dyslipidemia (mainly types Ila and Ilb) were significantly more frequent, violation of carbohydrate metabolism (fasting glycemic level $8.0+2.0$ $\mathrm{mmol} / \mathrm{I}$ ), a higher level of uricemia (from 397.8 to $660.5 \mathrm{mmol} / \mathrm{I}$ ) compared with the 1st group. The average level of IL- 6 in the serum of patients in group 1 was $1.46 \mathrm{pg} / \mathrm{ml}$, in group $2-14.03 \mathrm{pg} / \mathrm{ml}$, the average level of TNF-alpha in group 1 was $0.51 \mathrm{pg} / \mathrm{ml}$, in group $2-1.28 \mathrm{pg} / \mathrm{ml}$.

Conclusion: In GA patients with signs of MS, there is a significant increase in the production of key proinflammatory cytokines, namely IL-6, TNF-alpha. It was found that with a combination of MS and GA, the concentrations of IL-6, on average, 9.6 times, and TNF-alpha - 2.5 times, exceed the parameters of patients without signs of MS. A direct relationship was established between the expression of IL-6 and TNF-alpha with body mass index, as well as with insulin resistance and fluctuations in blood pressure. Thus, the cytokine imbalance is associated with increased risks of both cardiometabolic complications and the progressive course of GA

Disclosure of Interests: None declared.

DOI: 10.1136/annrheumdis-2021-eular.3016

\begin{tabular}{|l|l}
\hline AB0639 & EXOSOMES DERIVED FROM ENDOTHELIAL CELLS \\
PREVENT OSTEOBLAST APOPTOSIS IN STEROID- \\
INDUCED OSTEONECROSIS OF THE FEMORAL \\
HEAD RAT MODEL VIA THE PI3K/AKT/BCL-2 SIGNAL \\
PATHWAY
\end{tabular}

J. Sun ${ }^{1}$, W. Zheng ${ }^{2}$, Y. Zhang ${ }^{1}$, Z. Gu ${ }^{3} .{ }^{1}$ Affiliated Hospital of Nantong University, Department of Orthopaedics, Nantong, China; ${ }^{2}$ Affiliated Hospital of Nantong University, Research Center of Clinical Medicine, Nantong, China; ${ }^{3}$ Affiliated Hospital of Nantong University, Department of Rheumatology, Nantong, China

Background: Osteonecrosis of the femoral head (ONFH) is a common disease caused by many trauma factors and un-trauma factors. Among those un-trauma factors, steroid-induced osteonecrosis of the femoral head (SNFH) accounted for a large proportion and mainly concentrated in young people. SNFH has been reported as an irreversible disease and associated with the damage of blood vessels and the loss balance of bone homeostasis. Circulating endothelial progenitor cells (CEPCs), one part of circulating endothelial cells (CECs), are immature precursor cells with proliferative potential. The damage of vascular endothelial cells in SNFH has been confirmed by many studies, but the changes of CECs and CEPCs in the peripheral blood of patients with SNFH have not been studied yet.

Objectives: The objective of the study is to explore the number of CECs and CEPCs in SNFH patients and normal people and then investigate whether EC-secreted exosomes (EC-exos) could prevent the progression of SNFH in rat model and its mechanism of action.

Methods: We collect peripheral blood of 3 SNFH patients and 3 heathy people and detected the levels of CECs and CEPCs by Flow cytometer. TEM, NTA and western blot was used to characterize the isolated EC-exos. Annexin V-FITC/ $\mathrm{PI}$ double staining with flow cytometric analysis and western blot were used to evaluate MC3T3-E1 cells apoptosis. CCK-8, scratching experiment and transwell were used to evaluate MC3T3-E1 cells viability and migration ability. Micro-CT and morphological staining were used to evaluate the progress of SNFH in rat model.

Results: Firstly, we found that the number of CECs and CEPCs in the peripheral blood was decreased in SNFH patients than normal people. Then our results indicated that $\mathrm{EC}$-exos could improve the migration, viability and prevent apoptosis of osteoblasts under dexamethasone by activating the PI3K/ AKT/Bcl-2 signal pathway in vitro. Finally, our Micro-CT and morphological staining results in SNFH rat model revealed that EC-exos prevented the progression of SNFH.

Conclusion: EC-exos could enhance the cell viability and migration ability of osteoblasts under dexamethasone and play an anti-apoptosis role against steroids-induced osteoblast apoptosis by activating the PI3K/AKT/Bcl-2 signal pathway. EC-exos prevented the progression of SNFH in rat model.

\section{REFERENCES:}

[1] Zalavras CG, Lieberman JR. Osteonecrosis of the femoral head: evaluation and treatment. J Am Acad Orthop Surg. 2014;22(7):455-64.

[2] Microsurgery Department of the Orthopedics Branch of the Chinese Medical Doctor A, Group from the O, Bone Defect Branch of the Chinese Association of R, Reconstructive S, Microsurgery, Reconstructive Surgery Group of the Orthopedics Branch of the Chinese Medical A. Chinese Guideline for the Diagnosis and Treatment of Osteonecrosis of the Femoral Head in Adults. Orthop Surg. 2017;9(1):3-12.

[3] Mont MA, Jones LC, Hungerford DS. Nontraumatic osteonecrosis of the femoral head: ten years later. J Bone Joint Surg Am. 2006;88(5):1117-32.

[4] Yuan HF, Zhang J, Guo CA, Yan ZQ. Clinical outcomes of osteonecrosis of the femoral head after autologous bone marrow stem cell implantation: a meta-analysis of seven case-control studies. Clinics (Sao Paulo). 2016;71(2):110-3.

[5] Houdek MT, Wyles CC, Packard BD, Terzic A, Behfar A, Sierra RJ. Decreased Osteogenic Activity of Mesenchymal Stem Cells in Patients With Corticosteroid-Induced Osteonecrosis of the Femoral Head. J Arthroplasty. 2016;31(4):893-8.

Disclosure of Interests: None declared.

DOI: 10.1136/annrheumdis-2021-eular.3088

\section{$\mathrm{AB} 0640$ MORTALITY IN CALCIUM PYROPHOSPHATE CRYSTAL DEPOSITION DISEASE: PRELIMINARY DATA}

M. Eliseev ${ }^{1}$, A. Novikova ${ }^{1}$, O. Sheliabina ${ }^{1}$, M. Chikina ${ }^{1} .{ }^{1}$ VA Nasonova Research Institute of Rheumatology, Laboratory of Microcrystalline Arthritis, Moscow, Russian Federation 